\title{
Insomnia related to sleep apnoea: effect of long-term auto-adjusting positive airway pressure treatment
}

\author{
Xuân-Lan Nguyên*, Dominique Rakotonanahary*, Joël Chaskalovic ${ }^{\#}$ \\ and Bernard Fleury*
}

ABSTRACT: Insomnia related to sleep apnoea (IA) is highly prevalent, and its proper treatment is still debated. The aim of this study was to test the hypothesis that long-term auto-adjusting positive airway pressure (APAP) treatment improves IA symptoms.

80 patients (mean \pm SD age $54.9 \pm 10.6$ yrs, respiratory disturbance index (RDI) $45.0 \pm 24.6$ events $\cdot h^{-1}$ ) receiving APAP treatment were followed prospectively for 24 months. Somnolence and depression were assessed at baseline (T0) with the Epworth and the QD2A scales, respectively. Nightly APAP use was measured after 24 months of treatment (T24). The assessment of insomnia at T0 and T24 used the insomnia severity index (ISI). The combination of ISITO $\geqslant 15$ and ISIT0-ISIT24 $\geqslant 9$ defined the APAPresponding insomnia (APAP-RI) group. A logistic regression analysis identified the factors independently associated with the APAP-RI group.

The ISI (13.7 \pm 5.7 versus $8.2 \pm 6.3)$ decreased significantly from T0 to T24 $(p=0.0001)$ for the patients as a whole, with a mean decrease of $13.5 \pm 2.9$. Among the 39 insomniac subjects (T0), 20 belonged to the APAP-RI group (51\%). The Epworth score (OR 1.536, 95\% CI 1.093-2.159; $p=0.01$ ) and the RDI (OR 1.080, 95\% $\mathrm{Cl} 1.010-1.154 ; p=0.02$ ) increased the risk of belonging to the APAPRI group.

IA symptoms improved with APAP treatment, and improvement was associated with the initial severity of the disease and somnolence in our population.

KEYWORDS: Insomnia related to sleep apnoea, insomnia severity index, obstructive sleep apnoea syndrome

\footnotetext{
A close association between obstructive sleep apnoea syndrome (OSAS) and insomnia has frequently been reported in the literature [13], and a particular subtype of chronic insomnia in apnoeic subjects, described as insomnia related to sleep apnoea (IA), has been proposed for further research evaluation by the American Academy of Sleep Medicine (AASM) [4]. In the literature, the denomination of insomnia comorbid with sleep apnoea has also been mentioned, sharing with IA the notion of a possible inter-relationship between the two diseases. The co-occurrence of OSAS and insomnia can affect $50 \%$ of certain patient populations [5]. A simple explanation for the high frequency of this comorbidity may be the high prevalence of these two pathologies in the general population [6]. However, a causal relationship between these two entities is also possible; the wakefulness drive, which is hyperactive during insomnia, may be aggravated by the repeated arousals and microarousals that result from abnormal respiratory
}

events [7]. Understanding the mechanism or mechanisms underlying this pathological association is not merely of theoretical interest. The association between OSAS and pre-existing insomnia is responsible for debilitating daytime symptoms, such as excessive daytime sleepiness, impaired cognitive performance or concentration and decreased night-time sleep quality [5]. It has been hypothesised that sympathetic hyperstimulation in insomnia patients can potentially increase the cardiovascular risk associated with OSAS [8]. Suppressing abnormal respiratory events over a long period using the standard treatment, positive airway pressure (PAP) [9], might permit assessment of the evolution of insomnia under PAP, which, to the best of our knowledge, has not yet been attempted. This intervention approach is possible because we have recently reported that pre-existing insomnia does not have a significant impact on adherence to auto-adjusting positive airway pressure (APAP) treatment [5].
AFFILIATIONS

*Unité de Sommeil, Service de Pneumologie, Hôpital Saint-Antoine, and

"Dept of Mathematics, Institut Jean le Rond d'Alembert, Université Pierre et Marie Curie, Paris, France.

CORRESPONDENCE

X-L. Nguyên

Unité de Sommeil

Service de Pneumologie

Hôpital Saint-Antoine

184 rue du Faubourg Saint-Antoine 75012 Paris

France

E-mail: xuan-lan.nguyen@sat.aphp.fr

Received:

May 112011

Accepted after revision:

June 102012

First published online:

July 262012 
Having hypothesised that insomnia complaints would be influenced, to a certain extent, by APAP treatment, the aim of this prospective study was to observe the evolution of insomnia symptoms from the beginning of APAP treatment to the 24th month of follow-up in a population of OSAS patients whose baseline insomnia had already been assessed with validated self-report questionnaires $[10,11]$.

\section{METHODS}

The study was a prospective and observational study. Patients were referred by general practitioners and ear-nose-and-throat surgeons (Ile-de-France) to our sleep disorders clinic affiliated with an academic medical centre (Paris) to undergo a diagnostic sleep recording night for diagnosis of sleep apnoea syndrome. They presented with the main complaints of snoring or witnessed apnoeas with excessive daytime sleepiness.

Inclusion criteria for the study were: 1) the existence of a sleep apnoea syndrome, as defined by the AASM [12], warranting PAP treatment; and 2) the subject declaring an ongoing and regular use of APAP treatment at the 24th month of treatment, with APAP being the exclusive treatment for the OSAS.

Out of a sample of 148 consecutive OSAS patients who were fitted with an APAP device between November 2005 and March 2007 [5], 80 patients were included, who were still on treatment 24 months after their APAP treatment began.

The study was approved by the Institutional Review Board of the Société de Pneumologie de Langue Française.

\section{Procedures}

\section{Diagnostic procedures}

We performed ambulatory cardiorespiratory monitoring in a series of snoring patients with high pre-test probability of sleep apnoea syndrome, following the executive summary guidelines of the AASM $[13,14]$, with the exception that an apnoea/ hypopnoea index $>10$ events $\cdot \mathrm{h}^{-1}$ was used as the threshold defining OSAS. The portable monitor (CIDELEC, Gemmes sur Loire, France) analysed snoring, oxyhaemoglobin saturation and nasal airflow (by nasal cannula), and monitored respiratory effort with thoracic and abdominal strain gauges and a suprasternal pressure transducer [15].

The abnormal breathing events per hour of monitoring time and the time during which the oxygen saturation was $<90 \%$ were quantified and reported as the respiratory disturbance index (RDI) and the oxygen saturation $<90 \%$ value, respectively.

\section{Baseline self-report questionnaires}

All of the questionnaires were administered prior to initiating the APAP treatment (baseline; T0).

Insomnia was assessed by the insomnia severity index (ISI) at baseline (ISIT0) [10]. The ISI questionnaire consists of seven items that are scored by the patient from 0 to 4 . The maximum ISI score is 28. Significant insomnia (SI) was defined as an ISI score $\geqslant 15$. An ISI decrease of $\geqslant 9$ after the APAP treatment was considered to be a clinically significant improvement [16] and defined the APAP-responding insomnia (APAP-RI) phenotype in the SI group. The acronym APAP-NRI was consequently used to designate the subjects with APAP-non responding insomnia.
The subjective quality of sleep index was assessed with the Pittsburgh sleep quality index (PSQI) questionnaire at baseline (PSQIT0) [11], for which the maximum score is 21 and for which values $>5$ indicate poor sleep quality. The components of the PSQI score include subjective sleep quality, sleep latency, sleep duration, habitual sleep efficiency, sleep disturbances, use of sleep medications and daytime dysfunction. Each of these components is scored from 0 to 3 (with 0 indicating the absence of any difficulties and 3 indicating severe difficulties).

The subjective somnolence was measured with the Epworth Sleepiness Scale (ESS) at baseline [17], for which a value $\geqslant 11$ indicates excessive daytime somnolence [18].

The depression symptoms were assessed with the QD2A depression scale $[19,20]$. This instrument is a 13-item self-rated questionnaire of depressive symptomatology, comprising the following: 1) "I cannot get rid of adverse thoughts that go through my head"; 2) "I have no energy"; 3) "I do not appreciate things I used to like as fully as before"; 4) "I feel disappointed and disgusted with myself"; 5) "I feel helpless or blocked by the slightest thing I need do"; 6) "Right now I feel unhappier than most people"; 7) "I have the blues"; 8) "I have to force myself to do every little thing I have to do"; 9) "I feel my mind is not as clear as usual"; 10) "I am unable to make up my mind as easily as usual"; 11) "Right now I feel sad"; 12) "I have trouble doing the things I used to do"; and 13) "I feel my life is empty". This scale was administered at baseline only. Each item presents a statement that the subject answers as "true" or "false", and the score is the number of items the subject marked "true" and varies between 0 and 13. The threshold for a positive indication of depression is a score of 7 .

\section{Medications at TO}

The data included details on psychotropic medication use among subjects; hypnotics, anxiolytics and antidepressants were identified separately.

\section{4-month follow-up}

The ISI, PSQI and ESS assessments were re-administered to patients at the 24-month visit (T24). No cognitive-behavioural therapy (CBT) for insomnia was been started after initiating PAP therapy in the 80 subjects.

\section{Installing the APAP device}

As described above [5], the patients were fitted with APAP masks during a scheduled hospital visit the day after they received a positive diagnosis of sleep apnoea; the procedure was identical for all patients. During this visit, the patient attended a training session explaining the pathology and treatment of OSAS. A nasal mask was applied unless the patient could confirm that he or she was unable to breathe nasally; in such cases, a full-face mask was selected. Finally, the patient was given a 30-min practice session with the APAP device before beginning home treatment with optimally fitted equipment.

The device was an APAP device with initial minimum and maximum pressures that were empirically set at 6 and $12 \mathrm{cmH}_{2} \mathrm{O}$, respectively. 
Home treatment was monitored by a technician specialising in homecare medical appliances who had been contracted by the service provider. Following a routine procedure, the patients were visited by a technician on days 8 and 15, at the end of the first month, at the end of the sixth month and every 6 months thereafter until the 24th month. The APAP memory recordings (adherence, 95th percentile positive pressure (P95) and leaks) were collected at each visit. The mask was changed when there was leakage or discomfort, and a heated humidifier was provided to address nasobuccal dryness. A full-face mask was recommended when oronasal dryness persisted despite humidifier use.

Overnight oximetry recordings (PalmSAT 2500; NONIN Medical, Inc., Plymouth, MN, USA) were taken on two consecutive nights after verifying that the patient was sufficiently comfortable. Mechanical efficacy was defined as an oxyhaemoglobin desaturation index (ODI) $<10$ events $\cdot \mathrm{h}^{-1}$; in the case of an ODI $>10$ events $\cdot \mathrm{h}^{-1}$, the positive-pressure range was modified and additional treatment efficacy visits were scheduled [21, 22].

\section{APAP adherence at T24}

The data regarding APAP adherence at T24 were extracted from the memory recordings of the APAP device and were used to calculate the mean nightly APAP use, measured in hours, at 24 months, and the mean nightly APAP use/time slept (\% APAP useT24), with the time slept being assessed by the PSQI questionnaire.

\section{Statistical analyses}

The characteristics of the subjects in the different groups were expressed as mean $\pm S D$ or proportions (when appropriate). The differences between the two groups were compared using the unpaired t-test or the Chi-squared test (when appropriate). Statistical significance was defined as $p<0.05$. A logistic regression analysis was performed. The dependent variable was being in the SI group (ISIT0 $\geqslant 15$ ) and having a significant $(\geqslant 9)$ decrease in the ISI (i.e. being in the APAP-RI group), which was coded as yes $=1$ and no $=0$. Consequently, subjects in the APAP-NRI group were those subjects having an ISIT0 $\geqslant 15$ and a decrease in the ISI $<9$. The independent variables consisted of all the parameters that were significant in the univariate analyses along with age and body mass index (BMI), which are known to be potentially associated with insomnia [23, 24]. The ISI and the PSQI, which is closely related to the ISI [16], were not included in the model. The results were expressed as odds ratio (95\% confidence interval).

The analyses were performed using IBM SPSS Modeler 14 and IBM SPSS Statistics 19 (SPSS Inc., Chicago, IL, USA).

\section{RESULTS}

\section{Study population}

Initial sample

The initial sample consisted of 148 consecutive subjects (121 males and 27 females) who were prescribed APAP (mean \pm SD age $54.8 \pm 11.8 \mathrm{yrs}$, BMI $29.1 \pm 6.3 \mathrm{~kg} \cdot \mathrm{m}^{-2}$, ESST0 $12.2 \pm 5.4$, RDI $39.0 \pm 21.3$ events $\cdot h^{-1}$ and QD2A depression score $4.8 \pm 4.0$ ).

\section{APAP discontinuers}

Of the 148 consecutive APAP patients, 68 discontinued. 29 $(19.6 \%)$ declined it in the early weeks and 11 (7.4\%) APAPnonadherent subjects (adherence being defined by a PAP use $\geqslant 4 \mathrm{~h}$ per night) did so in the first 6 months of treatment. 28 (18.9\%) subjects were initially APAP adherent but stopped use prior to the 24-month follow-up. Among the 28, 10 (6.7\%) did not complete subsequent follow-up visits. In the remaining 18 $(12.2 \%)$ APAP-adherent subjects who sought alternative treatment, the OSAS treatment approach had to be reconsidered and alternative treatment modalities were discussed, including surgery, oral appliance therapy and diet.

\section{APAP continuers: study sample}

A final total of 80 patients (70 males and 10 females, age $54.9 \pm 10.6 \mathrm{yrs}$ and BMI $30.5 \pm 6.0 \mathrm{~kg} \cdot \mathrm{m}^{-2}$ ) were included in this study (fig. 1). The mean QD2A score in the study sample was $4.7 \pm 4.2 ; 25(31.2 \%)$ of the 80 subjects had QD2A scores $>7.23$ subjects were taking psychotropic drugs, 14 (61\%) were taking antidepressants and nine (39\%) were taking hypnotics.

While using APAP therapy, patients had a mean ODI of $3.4 \pm 2.0$ events $\cdot h^{-1}$, a mean RDI of $3.2 \pm 2.0$ events $\cdot h^{-1}$ and a mean $P 95$ of $10.7 \pm 2.6 \mathrm{hPa}$. The patients continued to use their APAP devices for a mean of $737 \pm 24$ days with a mean nightly APAP use of $5.1 \pm 2.3 \mathrm{~h}$ per night. At T24, the ESS scores were significantly lower $(7.4 \pm 5.0$ versus $13.2 \pm 5.4$ at $\mathrm{T} 0, \mathrm{p}=0.0001)$.

\section{Comparison between APAP continuers and discontinuers}

At baseline, no significant differences between the two groups were identified for age, ISIT0, PSQIT0 or QD2A scores, use of psychotropic medications or the "use of sleep medications" component of the PSQI. The subjects who abandoned the APAP therapy before T24 were significantly less somnolent and had lower BMIs and less severe sleep apnoea syndromes (table 1).

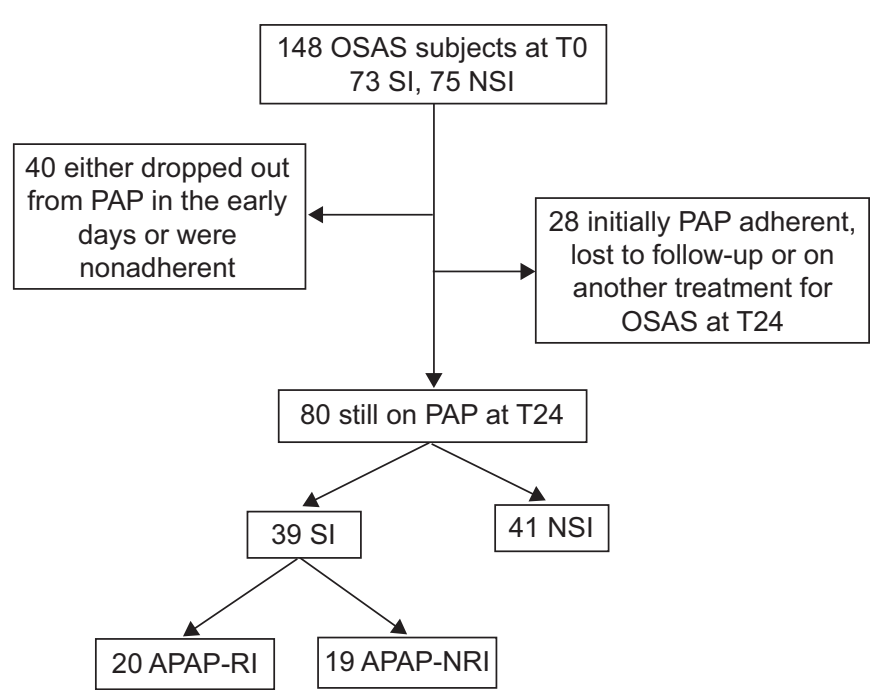

FIGURE 1. Patient flow diagram. OSAS: obstructive sleep apnoea syndrome TO: baseline; SI: with significant insomnia; NSI: without significant insomnia; PAP positive airway pressure; T24: 24-month follow-up; APAP-RI: adjusting positive airway pressure (APAP)-responding insomnia; APAP-NRI: APAP-nonresponding insomnia. 


\begin{tabular}{|c|c|c|c|}
\hline \multirow[t]{2}{*}{ TABLE 1} & \multicolumn{3}{|c|}{$\begin{array}{l}\text { f the } 80 \text { study subjects and the } 68 \\
\text { did not adhere to adjusting positive } \\
\text { re (APAP) treatment }\end{array}$} \\
\hline & $\begin{array}{l}\text { APAP } \\
\text { continuers }\end{array}$ & $\begin{array}{c}\text { APAP } \\
\text { discontinuers }\end{array}$ & $p$-value \\
\hline Subjects n & 80 & 68 & \\
\hline Age yrs & $54.9 \pm 10.6$ & $54.9 \pm 13.2$ & $0.98^{\circ}$ \\
\hline $\mathrm{BMI} \mathrm{kg} \cdot \mathrm{m}^{-2}$ & $30.5 \pm 6.0$ & $27.2 \pm 6.4$ & $0.002^{\circ}$ \\
\hline ESSTO & $13.2 \pm 5.5$ & $11.3 \pm 5.1$ & $0.03^{\circ}$ \\
\hline ISITo & $13.7 \pm 5.7$ & $14.1 \pm 4.7$ & $0.59^{\circ}$ \\
\hline QD2A scale & $4.7 \pm 4.2$ & $5.1 \pm 3.8$ & $0.57^{\circ}$ \\
\hline PSQITo & $8.2 \pm 3.7$ & $7.7 \pm 3.1$ & $0.40^{\circ}$ \\
\hline RDI events $\cdot h^{-1}$ & $45.0 \pm 24.6$ & $32.0 \pm 14.7$ & $0.0001^{\circ}$ \\
\hline $\mathrm{Sa}, \mathrm{O}_{2} \%$ & $15.4 \pm 20.8$ & $9.7 \pm 18.2$ & $0.09^{\circ}$ \\
\hline Sleep latency ${ }^{\#}$ min & $22.8 \pm 31$ & $20.3 \pm 22.4$ & $0.58^{\circ}$ \\
\hline Sleep duration" $h$ & $6.5 \pm 1.59$ & $6.7 \pm 1.30$ & $0.43^{\circ}$ \\
\hline $\begin{array}{l}\text { Psychotropic medication } \\
\text { use }\end{array}$ & $23(28.8)$ & $20(29)$ & $0.93^{+}$ \\
\hline Hypnotic drug use & $9(11.3)$ & $7(10.2)$ & $0.85^{+}$ \\
\hline $\begin{array}{l}\text { Antidepressant medication } \\
\text { use }\end{array}$ & $14(17.5)$ & $10(14.5)$ & $0.64^{+}$ \\
\hline Anxiolytic medication use & $12(15)$ & $15(21.7)$ & $0.27^{+}$ \\
\hline \multicolumn{4}{|c|}{$\begin{array}{l}\text { Data are presented as mean } \pm \text { SD or } n(\%) \text {, unless otherwise stated. BMI: body } \\
\text { mass index; ESS: Epworth Sleepiness Score; TO: at baseline; ISI: insomnia } \\
\text { severity index; PSQI: Pittsburgh sleep quality index; RDI: respiratory disturbance } \\
\text { index; } \mathrm{Sa}_{\mathrm{O}_{2}} \text { : arterial oxygen saturation. }{ }^{\#} \text { : derived from the PSQI questionnaire; } \\
\text { : obtained using the t-test; }{ }^{+} \text {: obtained using the Chi-squared test. }\end{array}$} \\
\hline
\end{tabular}

\section{Analysis of insomnia in the study sample}

\section{At TO}

Based on the threshold score of 15 for moderate-to-severe insomnia [10], 39 (49\%) patients were categorised as having SI and 41 were categorised as having nonsignificant insomnia (NSI). The characteristics of the SI and NSI groups are summarised in table 2.

The age, corpulence, baseline vigilance status and disease severity values of the SI and NSI subjects were not significantly different. Insomnia was confirmed in the SI subjects by a significant increase in sleep latency, a reduced total night-time sleep duration on the PSQI and a higher total PSQI score. The SI subjects used more psychotropic medications (hypnotics and antidepressants in particular) and had higher depression scores than did the NSI subjects.

\section{At T24}

The ISI $(13.7 \pm 5.7$ versus $8.2 \pm 6.3)$ and PSQI $(8.2 \pm 3.7$ versus $5.9 \pm 3.8)$ scores of the study population decreased significantly from T0 to T24 $(p=0.0001)$. Among the 39 patients with insomnia at baseline, 20 (51\%) had significant decreases (>9 points) in their ISI scores while using the APAP treatment (the APAP-RI group).

\section{Analysis of the dependent variable: being in the APAP-RI group}

Univariate analysis

The results of the comparison between APAP-RI $(n=20)$ and APAP-NRI $(n=19)$ subjects are summarised in table 3.

\begin{tabular}{|c|c|c|c|}
\hline \multirow[t]{2}{*}{ TABLE 2} & & \multirow[b]{2}{*}{$\mathrm{p}$-value } \\
\hline & SI & NSI & \\
\hline Subjects $\mathbf{n}$ & 39 & 41 & \\
\hline Age yrs & $53.7 \pm 9.7$ & $56.5 \pm 11.6$ & $0.20^{\circ}$ \\
\hline $\mathrm{BMI} \mathbf{k g} \cdot \mathrm{m}^{-2}$ & $31.5 \pm 6.1$ & $29.3 \pm 5.8$ & $0.08^{\circ}$ \\
\hline RDI events $\cdot h^{-1}$ & $45.9 \pm 26.8$ & $43.5 \pm 21.9$ & $0.75^{\circ}$ \\
\hline $\mathrm{Sa}, \mathrm{O}_{2}<90 \% \%$ & $11.9 \pm 13.7$ & $19.0 \pm 26.2$ & $0.15^{\circ}$ \\
\hline ESSTo & $14.0 \pm 5.6$ & $12.4 \pm 5.1$ & $0.14^{\circ}$ \\
\hline ISITo & $18.1 \pm 3.1$ & $8.5 \pm 3.1$ & $0.0001^{\circ}$ \\
\hline PSQITo & $10.4 \pm 3.3$ & $5.6 \pm 2.0$ & $0.0001^{\circ}$ \\
\hline QD2A depression score & $6.4 \pm 4.3$ & $2.7 \pm 3.0$ & $0.0001^{\circ}$ \\
\hline Sleep latency at $\mathrm{TO}^{\#} \min$ & $28.8 \pm 39.7$ & $15.4 \pm 12.3$ & $0.05^{\circ}$ \\
\hline Total sleep time at $\mathrm{TO}^{\#} \mathrm{~h}$ & $5.8 \pm 1.2$ & $7.4 \pm 1.5$ & $0.0001^{\circ}$ \\
\hline Psychotropic medication use & $17(43.6)$ & $6(14.6)$ & $0.004^{+}$ \\
\hline Hypnotic drug use & $8(20.5)$ & $1(2.4)$ & $0.01^{+}$ \\
\hline Antidepressant medication use & $11(28.2)$ & $3(7.3)$ & $0.01^{+}$ \\
\hline Anxiolytic medication use & $9(23.1)$ & $3(7.3)$ & $0.048^{+}$ \\
\hline
\end{tabular}

Data are presented as mean \pm SD or $n(\%)$, unless otherwise stated. BMI: body mass index; $\mathrm{RDI}$ : respiratory disturbance index; $\mathrm{Sa}_{\mathrm{O}_{2}}$ : arterial oxygen saturation; ESS: Epworth Sleepiness Score; ISI: insomnia severity index; PSQI: Pittsburgh sleep quality index. ${ }^{\#}$ : derived from the PSQI questionnaire; $\because$ : obtained using the t-test; ${ }^{+}$: obtained using the Chi-squared test.

Baseline total scores for the ISI and the PSQI were of similar magnitude in the two groups, with difficulty in falling asleep being significantly more severe in the APAP-RI group whatever the questionnaire used.

The RDI, ESS and \% APAP useT24 differed significantly between the two groups. The subjects in the APAP-RI group had more severe sleep apnoea, had higher baseline somnolence scores, and were more adherent to their APAP therapy relative to their sleep time than were those in the APAP-NRI group. It is noteworthy that the APAP efficacy was comparable in the two groups, as shown by the values of the ODI under APAP therapy, which were not significantly different. The values of the PSQI remained high in the APAP-NRI group, with the highest values of all the components of the score (apart from the item "sleep duration"), relative to the APAP-RI group; the item value for use of a sleeping medication, which did not differ in the two groups at baseline, was found to be significantly more elevated in the APAP-NRI group at T24.

The RDI, the baseline ESS and the \% APAP useT24 were consequently included in the logistic regression model, along with the age and BMI for the previously mentioned reasons.

\section{Multivariate analysis}

The results of the logistic regression analysis are shown in table 4 .

The precision of the model was $87.2 \%$, meaning that $87.2 \%$ of subjects were correctly classified in this model. The contributions of the RDI, \% APAP useT24, ESS, BMI and age to the construction of the model were, respectively, $40 \%, 24 \%, 18 \%$, $11 \%$ and $7 \%$. 


\begin{tabular}{|c|c|c|c|}
\hline \multicolumn{4}{|c|}{$\begin{array}{l}\text { Comparison of adjusting positive airway } \\
\text { pressure-responding insomnia (APAP-RI) and } \\
\text { APAP-nonresponding insomnia (APAP-NRI) } \\
\text { subjects at } 24 \text { months (T24) using univariate } \\
\text { analysis }\end{array}$} \\
\hline & APAP-RI & APAP-NRI & p-value \\
\hline \multicolumn{4}{|l|}{ Subjects n } \\
\hline Age yrs & $52.0 \pm 8.0$ & $54.9 \pm 11.6$ & 0.37 \\
\hline BMI $\mathbf{k g} \cdot \mathrm{m}^{-2}$ & $31.7 \pm 7.8$ & $31.7 \pm 4.3$ & 0.99 \\
\hline RDI events $\cdot h^{-1}$ & $55.7 \pm 28.3$ & $35.1 \pm 21.5$ & 0.02 \\
\hline ESSTO & $16.6 \pm 4.8$ & $11.6 \pm 5.7$ & 0.005 \\
\hline Use of psychotropics at TO & $6(30)$ & $11(58)$ & $0.27^{\bullet}$ \\
\hline QD2A score & $6.7 \pm 4.3$ & $7 \pm 4.2$ & 0.83 \\
\hline ISITo items & $18.7 \pm 2.8$ & $18.3 \pm 3.0$ & 0.72 \\
\hline Difficulty falling sleep & $1.0 \pm 1.3$ & $2.1 \pm 1.0$ & 0.009 \\
\hline Difficulty staying asleep & $2.8 \pm 1.0$ & $2.7 \pm 0.9$ & 0.83 \\
\hline Early awakening & $2.2 \pm 1.5$ & $2.2 \pm 1.3$ & 0.99 \\
\hline Dissatisfaction with current sleep & $3.6 \pm 0.5$ & $3.2 \pm 0.6$ & 0.03 \\
\hline Interference with daily functioning & $3.3 \pm 0.6$ & $3.1 \pm 0.5$ & 0.16 \\
\hline Noticeable to others & $2.8 \pm 1.3$ & $2.4 \pm 1.1$ & 0.41 \\
\hline Worry about current sleep & $3.2 \pm 0.7$ & $2.8 \pm 0.8$ & 0.13 \\
\hline PSQITo components & $10.0 \pm 2.7$ & $11.7 \pm 3.2$ & 0.07 \\
\hline Subjective sleep quality & $2.5 \pm 0.7$ & $2.0 \pm 0.6$ & 0.02 \\
\hline Sleep latency & $0.7 \pm 1.0$ & $1.7 \pm 0.9$ & 0.001 \\
\hline Sleep duration & $1.7 \pm 0.9$ & $1.5 \pm 0.8$ & 0.7 \\
\hline Habitual sleep efficiency & $0.9 \pm 1.2$ & $1.6 \pm 1.3$ & 0.05 \\
\hline Sleep disturbances & $1.7 \pm 0.8$ & $2.2 \pm 0.5$ & 0.02 \\
\hline Use of sleeping medication & $0.7 \pm 1.3$ & $1.1 \pm 1.3$ & 0.3 \\
\hline $\begin{array}{l}\text { Daytime dysfunction over the last } \\
\text { months }\end{array}$ & $1.9 \pm 1.2$ & $1.5 \pm 1.0$ & 0.3 \\
\hline Self-declared sleep latency at TO $\mathrm{min}$ & $19.5 \pm 25.9$ & $41.4 \pm 51.5$ & 0.10 \\
\hline Self-declared total sleep time at TO $h$ & $5.7 \pm 1.2$ & $5.7 \pm 1.4$ & 0.92 \\
\hline Nightly APAP use at T24 & $6.1 \pm 1.7$ & $4.7 \pm 2.6$ & 0.054 \\
\hline APAP use at T24 $\%$ & $94.2 \pm 9.4$ & $70.7 \pm 34.4$ & 0.005 \\
\hline ESST24 & $6.5 \pm 4.2$ & $11.1 \pm 5.9$ & 0.008 \\
\hline ODI events $\cdot h^{-1}$ & $3.0 \pm 2.1$ & $3.4 \pm 2.0$ & 0.55 \\
\hline ISIT24 & $5.2 \pm 3.1$ & $17.1 \pm 4.0$ & $<0.0001$ \\
\hline ISIT24 items & & & \\
\hline Difficulty falling sleep & $0.3 \pm 0.4$ & $1.9 \pm 1.2$ & $<0.0001$ \\
\hline Difficulty staying asleep & $1.2 \pm 0.7$ & $2.3 \pm 0.9$ & $<0.0001$ \\
\hline Early awakening & $0.5 \pm 0.5$ & $2.5 \pm 1.3$ & $<0.0001$ \\
\hline Dissatisfaction with current sleep & $1.0 \pm 0.8$ & $2.4 \pm 1.1$ & $<0.0001$ \\
\hline Interference with daily functioning & $0.95 \pm 0.99$ & $3.0 \pm 0.7$ & $<0.0001$ \\
\hline Noticeable to others & $0.8 \pm 1.1$ & $2.4 \pm 1.0$ & $<0.0001$ \\
\hline Worry about current sleep & $0.7 \pm 1.1$ & $2.6 \pm 1.1$ & $<0.0001$ \\
\hline PSQIT24 components & $4.3 \pm 1.7$ & $10.4 \pm 4.2$ & $<0.0001$ \\
\hline Subjective sleep quality & $0.7 \pm 0.7$ & $1.5 \pm 0.7$ & $<0.0001$ \\
\hline Sleep latency & $0.4 \pm 0.6$ & $1.8 \pm 0.8$ & $<0.0001$ \\
\hline Sleep duration & $0.9 \pm 0.7$ & $1.3 \pm 0.9$ & 0.09 \\
\hline Habitual sleep efficiency & $0.3 \pm 0.7$ & $1.4 \pm 1.2$ & 0.002 \\
\hline Sleep disturbances & $0.9 \pm 0.6$ & $1.7 \pm 0.7$ & $<0.0001$ \\
\hline Use of sleeping medication & $0.3 \pm 0.6$ & $0.9 \pm 1.4$ & 0.04 \\
\hline $\begin{array}{l}\text { Daytime dysfunction over the last } \\
\text { months }\end{array}$ & $1.0 \pm 0.8$ & $1.7 \pm 0.9$ & 0.01 \\
\hline Self-declared sleep latency at T24 min & $7.9 \pm 9.1$ & $28.4 \pm 28.1$ & 0.003 \\
\hline Self-declared total sleep time at T24 h & $6.9 \pm 1.6$ & $5.8 \pm 1.7$ & 0.04 \\
\hline 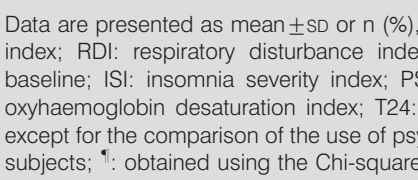 & $\begin{array}{l}\text { unless other } \\
\text { X; ESS: Eph } \\
\text { SQI: Pittsburc } \\
24 \text { months. } \\
\text { ychotropics ( } \\
\text { d test. }\end{array}$ & $\begin{array}{l}\text { stated. BMI } \\
\text { Sleepiness } \\
\text { sleep quality } \\
\text { obtained usin } \\
\text { in APAP-RI an }\end{array}$ & $\begin{array}{l}\text { ody mass } \\
\text { core; TO: } \\
\text { dex; ODI: } \\
\text { the t-test, } \\
\text { APAP-NRI }\end{array}$ \\
\hline
\end{tabular}

The variables that were independently and positively associated with belonging to the APAP-RI group were the ESS (OR $1.536,95 \%$ CI 1.093-2.159) and the RDI (OR 1.080, 95\% CI 1.010-1.154). Age (OR 0.832, 95\% CI 0.697-0.994) and BMI (OR $0.703,95 \%$ CI $0.522-0.947$ ) were negatively associated with inclusion in the APAP-RI group. The analysis showed a trend for a positive association between inclusion in the APAP-RI group and \% APAP useT24 (OR 1.124, 95\% CI 0.986-1.280).

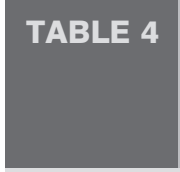

Logistic regression analysis of variables associated with the risk of belonging to the adjusting positive airway pressure-responding insomnia group

Variable

OR $(95 \% \mathrm{Cl})$

\section{Age yrs \\ BMI $\mathrm{kg} \cdot \mathrm{m}^{-2}$ \\ APAP useT24 \% \\ ESS \\ RDI events $\cdot h^{-1}$}

$0.832(0.697-0.994)$

$0.703(0.522-0.947)$

$1.124(0.986-1.280)$

$1.536(1.093-2.159)$

$1.080(1.010-1.154)$

BMI: body mass index; APAP: auto-adjusting positive ainway pressure; APAP useT24: mean nightly APAP use/time slept, time slept being assessed by the Pittsburgh sleep quality index questionnaire; ESS: Epworth Sleepiness Score RDI: respiratory disturbance index.

\section{DISCUSSION}

Nearly $50 \%$ of this sample of 80 OSAS subjects using long-term APAP therapy had a clinically significant complaint of insomnia prior to starting APAP. Half of the subjects who initially presented with significant insomnia reported a clinically significant decrease in their insomnia symptoms after 24 months of regular APAP use. The factors that were associated with this change included the RDI, the marker of the severity of the sleep apnoea syndrome and ESSTO.

The OSAS population in this study was part of a larger group of 148 subjects who were followed for $2 \mathrm{yrs}$ and were described in an earlier study [5]. Their anthropometric and polygraphic profiles were comparable to those of typical OSAS patients in clinical settings $[25,26]$.

The initiation and follow-up of the APAP treatment was conducted as described in previous studies $[5,22]$. The mechanical efficacy of the APAP treatment was confirmed in all patients by repeated oximetry measurements while they were receiving the therapy $[27,28]$, with a mean ODI of $3.4 \pm 2.1$ events $\cdot h^{-1}$ over two nights.

Of the 148 subjects in the initial group, 68 (45.9\%) eventually abandoned the APAP therapy before the end of 24 months; 29 $(19.6 \%)$ of these subjects stopped using the device in the early weeks, which is consistent with previously reported rates of PAP discontinuation, in which $14-30 \%$ of subjects no longer used PAP at the end of a 3-month follow-up [29], and with the $30-60 \%$ PAP-adherence estimates in the literature [30-35]. Consistent with previous findings [36-38], the subjects who stopped using the APAP treatment were less somnolent, had less severe OSAS and were less compliant with their APAP therapy. In addition, the mean nightly APAP use in our population was consistent with recently published data $[29,39,40]$.

Insomnia was assessed using the ISI score. The reliability and the validity of the ISI for detecting cases of insomnia were confirmed in a recent large study by MoRIN et al. [16]. We administered the ISI questionnaire in its French version [16], as previously used in OSAS patients to define insomnia [2]. We chose to use the ISI with a rigorous cut-off of 15 , as has been recommended by BASTIEN et al. [10] and as has previously been 
used in studies of similar populations in similar contexts [2]; this choice allows further comparisons with the pre-existing literature. A cut-off value of 15 is considered to be a stringent threshold [16]. Using a threshold value of 15, 49\% of our sleep apnoea subjects were found to be insomniac, which is consistent with previous data [1-3]. These subjects also had higher baseline depression scores and, according to the PSQI, lower sleep quality, increased sleep latency, reduced night-time sleep at baseline and consumed more psychotropic medications.

The ISI has also proven to be sensitive to treatment responses in clinical patients and can thus be used to monitor changes during treatment. A score change of -8.4 points has been shown to be associated with at least a moderate improvement in insomnia symptoms [16]. To our knowledge, the ISI change in apnoeic subjects being treated with APAP has not yet been reported. We defined a minimum score change of nine points between T0 and T24 as significant improvement in insomnia symptoms under the APAP treatment. According to these criteria (ISIT0 $\geqslant 15$ and change score $\geqslant 9$ ), APAP-responding insomnia was identified in $51 \%$ of the patients with baseline insomnia in our study sample. The association of insomnia and sleep apnoea is frequent [1-3]. The denomination insomnia related to sleep apnoea or insomnia comorbid with sleep apnoea implies a causal relationship between insomnia symptoms and OSAS. Our results suggest the existence of such a relationship in the 20 patients who showed a significant improvement. In univariate analysis, those subjects who were most prone to improving their baseline level of insomnia (APAP-RI subjects) presented with higher RDI, greater somnolence according to the ESS and worse quality of sleep (according to the specific items of the PSQI pertaining to the subjective quality of sleep, sleep efficiency and sleep disturbances) than the APAP-NRI subjects, and were also more compliant to their APAP. It is well known [37] that symptomatic and severe OSAS subjects are consequently more encouraged to persevere with their APAP treatment. As we showed in our earlier study [5] and confirmed in this study, PAP treatment is not more poorly tolerated in insomniac patients. If PAP treatment is a proper treatment for insomnia related to sleep apnoea, it may not only relieve the insomnia complaint but also prevent the vascular risk eventually associated with the sympathetic hyperactivity and the sleep restriction.

The multivariate analysis confirms the independent association between inclusion in the APAP-RI group and the Epworth score and the RDI.

It is certainly easier to understand how sleep apnoea syndrome can generate insomnia (abnormal respiratory events related micro-arousals causing lighter sleep) and subsequently how some of our subjects with sleep apnoea and insomnia could improve with PAP, and hence the relationship between the RDI and inclusion in the APAP-RI group.

The relationship between somnolence and insomnia in this context is probably more complex: previous studies have shown that insomnia and suspected OSA (snoring and witnessed apnoeas) were independently associated with daytime sleepiness [41], via sleep fragmentation, a phenomenon occurring in either disease. Furthermore, a potential worsening of the sleep apnoea syndrome by insomnia has been evoked, with sleep fragmentation causing an increased collapsibility of the upper airway. The positive association between the ESS and inclusion in the APAP-RI group could be explained by the beneficial effect of PAP on sleep fragmentation, whatever the cause. Thus, it appears that insomnia and sleep apnoea are likely to be related via diverse pathways.

Specific insomnia treatment may certainly be needed in insomniac subjects who fail to improve. Morin et al. [42] have already shown the long-term benefits of early adjuvant CBT in chronic insomnia. The efficacy of combined cognitive-behavioural therapy and PAP has already been demonstrated in a small pilot study by KRAKOW et al [43]. This approach might not be necessary for all of the OSAS patients affected by insomnia (39-50\%), but it might be appropriate for those subjects who fail to improve. Intervention studies involving CBT and PAP in OSAS subjects would confirm their combined indication.

We are conscious of the limitations of our study. This study is a population-based intervention study with no control arm. A controlled study comparing subjects treated with effective APAP to subjects using a sham PAP would be required to confirm and clarify the beneficial effects of APAP on insomnia symptoms. Possibilities for further studies might be suggested by our preliminary results. Insomnia symptoms were certainly not the chief complaints in our patients, who were referred to our sleep centre for evaluation of nocturnal or diurnal disorders highly suggestive of sleep apnoea, including snoring and excessive daytime sleepiness. However, in some patients, the two pathologies can appear to be so much intertwined that the clinical consequences of the first disease may no longer be easily distinguished from those of the second disease, illustrating the comorbidity between sleep apnoea and insomnia. This is an issue studies in this field will have to deal with as no consensus definition for the comorbidity or the association between sleep apnoea and insomnia has actually been agreed. Given the complexity of this relationship between insomnia and sleep apnoea, and the design of the study, our results can certainly not be extrapolated to a population with insomnia as the referral complaint in whom a sleep apnoea syndrome would have secondarily been diagnosed, and treated with PAP. We did not repeat the ISI assessment in the subjects who discontinued, which could have enabled a better understanding of the eventual responsibility of insomnia for the failure to use APAP in the long term. If the treatment aggravates insomnia symptoms, a potential negative impact of pre-existing insomnia on APAP adherence cannot be ruled out. Nevertheless, our data show that the baseline ISI, PSQI and QD2A scores of those who discontinued the APAP therapy were comparable with the scores of those who persisted with it. Because it is known that a multiplicity of factors that are highly variable between individuals are predictive of PAP adherence [29], presumably the decision to abandon APAP treatment cannot be attributable to insomnia alone.

\section{Conclusions}

Half of our OSAS patients with baseline significant insomnia were no longer insomniac on PAP treatment. The severity of the sleep apnoea syndrome, as measured by the RDI, and a higher level of somnolence at baseline, according to the ESS, were associated with significant improvement of insomnia 
from the long-term APAP treatment in our population of apnoeic subjects with insomnia.

Additional larger and controlled studies are needed to confirm these findings and to refine the assessment of insomnia comorbid with sleep apnoea.

\section{STATEMENT OF INTEREST}

None declared.

\section{REFERENCES}

1 Krakow B, Melendrez D, Ferreira E, et al. Prevalence of insomnia symptoms in patients with sleep-disordered breathing. Chest 2001; 120: 1923-1929.

2 Smith S, Sullivan K, Hopkins W, et al. Frequency of insomnia report in patients with obstructive sleep apnoea hypopnea syndrome (OSAHS). Sleep Med 2004; 5: 449-456.

3 Krell SB, Kapur VK. Insomnia complaints in patients evaluated for obstructive sleep apnea. Sleep Breath 2005; 9: 104-110.

4 Edinger JD, Bonnet MH, Bootzin RR, et al. Derivation of research diagnostic criteria for insomnia: report of an American Academy of Sleep Medicine Work Group. Sleep 2004; 27: 1567-1596.

5 Nguyên XL, Chaskalovic J, Rakotonanahary D, et al. Insomnia symptoms and APAP adherence in OSAS patients: a descriptive study using data mining methods. Sleep Med 2010; 11: 777-784.

6 Stradling JR, Davies RJ. Obstructive sleep apnoea-hypopnoea syndrome: definitions, epidemiology, and natural history. Thorax 2004; 59: 73-78.

7 Lavie P. Insomnia and sleep-disordered breathing. Sleep Med 2007; 8: Suppl. 4, S21-S25.

8 Beneto A, Gomez-Siurana E, Rubio-Sanchez P. Comorbidity between sleep apnea and insomnia. Sleep Medicine Rev 2009; 13: 287-293.

9 Sullivan CE, Issa FG, Berthon-Jones M, et al. Reversal of obstructive sleep apnoea by continuous positive airway pressure applied through the nares. Lancet 1981; 1: 862-865.

10 Bastien $\mathrm{CH}$, Vallieres A, Morin CM. Validation of the insomnia severity index as an outcome measure for insomnia research. Sleep Med 2001; 2: 297-307.

11 Buysse DJ, Reynolds CF III, Monk TH, et al. The Pittsburgh Sleep Quality Index: a new instrument for psychiatric practice and research. Psychiatry Res 1989; 28: 193-213.

12 American Academy of Sleep Medicine Task Force. Sleep-related breathing disorders in adults: recommendations for syndrome definition and measurement techniques in clinical research. Sleep 1999; 22: 667-689.

13 ATS/ACCP/AASM Taskforce Steering Committee. Executive summary on the systematic review and practice parameters for portable monitoring in the investigation of suspected sleep apnea in adults. Am J Respir Crit Care Med 2004; 169: 1160-1163.

14 Collop NA, Anderson WM, Boehlecke B, et al. Clinical guidelines for the use of unattended portable monitors in the diagnosis of obstructive sleep apnea in adult patients. Portable Monitoring Task Force of the American Academy of Sleep Medicine. J Clin Sleep Med 2007; 3: 737-747.

15 Meslier N, Simon I, Kouatchet A, et al. Validation of a suprasternal pressure transducer for apnea classification during sleep. Sleep 2002; 25: 753-757.

16 Morin CM, Belleville G, Bélanger L, et al. The insomnia severity index: psychometric indicators to detect insomnia cases and evaluate treatment response. Sleep 2011; 34: 601-608.

17 Johns MW. A new method for measuring daytime sleepiness: the Epworth Sleepiness scale. Sleep 1991; 14: 540-545.

18 Punjabi NM, Bandeen-Roche K, Young T. Predictors of objective sleep tendency in the general population. Sleep 2003; 26: 678-683.
19 Pichot $\mathrm{P}$, Boyer $\mathrm{P}$, Pull CB, et al. An auto-assessing questionnaire of depressive symptoms: the QD2 score. Construction, metrologic properties. [Un questionnaire d'auto-évaluation de la symptomatologie depressive: le QD2. Construction, structure factorielle, propriétés métrologiques.] Rev Psychol Appl 1984; 3: 229-250.

20 Pichot $\mathrm{P}$, Boyer P, Pull CB, et al. The QD2 score. The QD2A abbreviated version. [Le questionnaire QD2. La forme abrégée QD2A.] Rev Psychol Appl 1984; 4: 323-340.

21 Lévy P, Pépin JL, Deschaux-Blanc C, et al. Accuracy of oximetry for detection of respiratory disturbances in sleep apnea syndrome. Chest 1996; 109: 395-399.

22 Nguyên XL, Rakotonanahary D, Chaskalovic J, et al. Residual subjective daytime sleepiness under APAP treatment in initially somnolent apnea patients: a pilot study using data mining methods. Sleep Med 2008; 9: 511-516.

23 Kamel NS, Gammack JK. Insomnia in the elderly: cause, approach, and treatment. Am J Med 2006; 119: 463-469.

24 Watson NF, Goldberg J, Arquelles L, et al. Genetic and environmental influences on insomnia, daytime sleepiness and obesity in twins. Sleep 2006; 29: 645-649.

25 Massie CA, Hart RW. Clinical outcomes related to interface type in patients with obstructive sleep apnea/hypopnea syndrome who are using continuous positive airway pressure. Chest 2003; 123: 1112-1118.

26 Berry RB, Hill G, Thompson L, et al. Portable monitoring and autotitration versus polysomnography for the diagnosis and treatment of sleep apnea. Sleep 2008; 31: 1423-1431.

27 Stradling JR. Reducing the cost of treating obstructive sleep apnea: good news for patients. Am J Respir Crit Care Med 2004; 170: 1143-1144.

28 Mulgrew AT, Fox N, Ayas NT, et al. Diagnosis and initial management of obstructive sleep apnea without polysomnography: a randomized validation study. Ann Intern Med 2007; 146: 157-166.

29 Weaver TE, Maislin G, Dinges DF, et al. Relationship between hours of nightly APAP use and achieving normal levels of sleepiness and daily functioning. Sleep 2007; 30: 711-719.

30 Weaver TE, Kribbs NB, Pack AI, et al. Night-to-night variability in nightly APAP use over the first three months of treatment. Sleep 1997; 20: 278-283.

31 Engleman HM, Martin SE, Douglas NJ. Adherence with APAP therapy in patients with the sleep apnoea/hypopnoea syndrome. Thorax 1994; 49: 263-266.

32 Reeves-Hoche MK, Meck R, Zwillich CW. Nasal APAP: an objective evaluation of patient adherence. Am J Respir Crit Care Med 1994; 149: 149-154.

33 Kribbs NB, Pack AI, Kline LR, et al. Objective measurement of patterns of nasal Nightly APAP use by patients with obstructive sleep apnea. Am Rev Respir Dis 1993; 147: 887-895.

34 Krieger J. Long-term adherence with nasal continuous positive airway pressure (APAP) in obstructive sleep apnea patients and nonapneic snorers. Sleep 1992; 15: S42-S46.

35 Sanders MH, Gruendl CA, Rogers RM. Patient adherence with nasal APAP therapy for sleep apnea. Chest 1986; 90: 330-333.

36 Popescu G, Latham M, Allgar V, et al. Continuous positive airway pressure for sleep apnoea/hypopnoea syndrome: usefulness of a 2 week trial to identify factors associated with long term use. Thorax 2001; 56: 727-733.

37 Pelletier-Fleury N, Rakotonanahary D, Fleury B. The age and other factors in the evaluation of adherence with nasal continuous positive airway pressure for obstructive sleep apnea syndrome. A Cox's proportional hazard analysis. Sleep Med 2001; 2: 225-232.

38 Kohler M, Smith D, Tippett V, et al. Predictors of long-term adherence with continuous positive airway pressure. Thorax 2010; 65: 829-832.

39 Meurice JC, Ingrand $\mathrm{P}$, Portier F, et al. A multicentre trial of education strategies at APAP induction in the treatment of severe sleep apnoea-hypopnoea syndrome. Sleep Med 2007; 8: 37-42. 
40 Weaver TE, Sawyer AM. Adherence to continuous positive airway pressure treatment for obstructive sleep apnea: implications for future interventions. Indian J Med Res 2010; 131: 245-258.

41 Wickwire EM, Collop NA. Insomnia and sleep-related breathing disorders. Chest 2010; 137: 1449-1463.
42 Morin CM, Vallières A, Guay B, et al. Cognitive behavioural therapy, singly and combined with medication, for persistent insomnia: a randomized controlled trial. JAMA 2009; 301: 2005-2015.

43 Krakow B, Melendrez D, Lee SA, et al. Refractory insomnia and sleep-disordered breathing: a pilot study. Sleep Breath 2004; 8: 15-29. 